\title{
FILOSOFIA NO ENSINO MÉDIO: REFLEXÕES SOBRE A PRÁTICA DOCENTE
}

\section{PHILOSOFY IN HIGH SCHOLL: REFLECTIONS ABOUT THE TEACHER PRACTICE}

Eduardo Revelante Netto'

\begin{abstract}
Resumo: Este trabalho tem por finalidade pensar questões pertinentes sobre a Filosofia a sua natureza e a sua relação com a sociedade. Os desafios enfrentados pelos docentes para adequar, transformar a filosofia em uma disciplina do currículo escolar do ensino médio e as implicações decorrentes dessa condição de uma disciplina a ser ensinada. Tal condição nos leva a questionar qual é o papel da filosofia nesse contexto, assim como o desenvolvimento de uma metodologia de ensino que consiga atender as demandas sociais e alcançar os objetivos propostos.
\end{abstract}

Palavras-chave: filosofia; ensino; ensino médio.

\begin{abstract}
This work aims to think pertinent questions about the Philosophy its nature and its relation with the society. The challenges faced by teachers to adapt, to transform Philosophy into a discipline of the high school curriculum and the implications of this condition of a discipline to be taught. This condition leads us to question the role of Philosophy in this context, as well as the development of a teaching methodology that can meet the social demands and achieve the proposed objectives.
\end{abstract}

Keywords: philosophy; teaching; high school.

\section{INTRODUÇÃO}

O que é filosofia? Como ela se relaciona com a sociedade? Quais as implicações de transformá-la em uma disciplina do ensino médio? Há várias definições para filosofia, optarei pela definição que diz que filosofia se propõe a estabelecer um pensar crítico sobre a realidade. Sendo esse aspecto inerente da sua natureza, como que ela vai se inserir na sociedade? Qual seu papel social? A filosofia mesmo assumindo uma condição reducionista de disciplina, pode ser empregada no ambiente escolar para se repensar os conceitos que permeiam o agir humano e estruturam a realidade.

Se para o Estado os propósitos da filosofia no ensino médio ficam circunscritos ao desenvol1 E-mail: <eduardorevelante@gmail.com> 
vimento de habilidades para o exercício da cidadania, este trabalho tem como intuito alargar o horizonte de percepção do papel que a filosofia pode vir a ter na sociedade. Para isso, proponho uma metodologia de ensino pautada em problemas filosóficos e estabelecendo um diálogo entre filosofia e a arte. A partir de uma abordagem transversal explorando o caráter provocativo, subversivo e questionador que a arte pode assumir. Dessa forma, potencializando o desenvolvimento das atividades de filosofia no ensino médio. Essa aproximação com a arte tem por objetivo inicial despertar uma sensibilidade, uma atitude filosófica para uma análise da realidade, pois a arte tem essa capacidade de instigar o interesse e a curiosidade dos estudantes.

Por último, faço uma breve exposição sobre a experiência docente do ensino de filosofia em escola pública. Abordando principalmente a questão da segregação e da não valorização da filosofia em relação as demais disciplinas que compõem a grade curricular escolar.

\section{REFLEXÕES SOBRE A FILOSOFIA E SEU ENSINO NO ENSINO MÉDIO}

\section{1 Qual é o lugar da filosofia na sociedade?}

O filósofo quer libertar o mundo da ignorância humana. E, um dos primeiros movimentos nesse sentido pode ser percebido no personagem Sócrates de Platão. Na Alegoria da Caverna esse propósito é evidenciado. A filosofia se propõe a estabelecer um pensamento crítico sobre o pensar e o agir humano. Ela procura analisar a relação entre o conceito e o seu respectivo objeto, a validade a coerência do que é elencado no plano conceitual e sua existência/manifestação e correspondência no mundo. O conceito é resultado, é produto, é fruto de um pensamento estabelecido, suscitado racionalmente por um sujeito que vivencia a experiência do mundo empírico. Ele expressa a significação que essa experiência assume para o sujeito. O conceito não tem caráter universal. Xavier discorre sobre o significado que o conceito assume para Nietzsche:

(...) conceitos não são se não resíduos de metáforas e que estas, por sua vez, resultam de um complexo processo constituídos por diferentes transformações e transposições analógicas e singulares que têm início pela maneira que somos afetados pelas coisas. Desde essas primeiras reações, excitações nervosas são convertidas em imagens que, sofrendo uma segunda transposição e submetidas à identificação do não idêntico, acabam por culminar na linguagem, no entanto, ao se esquecerem de sua misteriosa proveniência, conceitos pretendem-se objetivos, universais e verdadeiros espelhos das coisas (XAVIER, 2010, p. 5).

Assim, diferente de significado, que nos remete a instauração de um conceito universal, o conceito enquanto uma significação adquirida pela experiência real manifestada de um ser no mundo, que vive, sente, e pensa o objeto para posteriormente defini-lo de forma singular. Há um consenso geral sobre a correspondência de determinado objeto e seu conceito, mas o sujeito que o vive, o pensa, o senti, Ihe atribuem elementos qualitativos únicos, cada um vive e estabelece um conceito com particularidades, tornando cada experiência única. Cada sujeito cria para si uma visão de mundo singular, desde pequenas nuanças, por vezes similares, compartilhados até a instauração de mundos incongruentes, incompatíveis, conflitantes. Visões de mundo que se complementam, ou se repelem. Os esquemas conceituais que estruturam aquilo que definimos como realidade, geram tensões, e é justamente estas visões singulares que levam a se repensar o estabelecido, em um movimento incessante.

Assim, o mundo adquire uma significação quando se estabelece conceitos que estruturam 
essa realidade. E que realidade é essa? Circunscrita ao tempo presente. Os conceitos são transitórios e efêmeros, mudam com o movimento da sociedade, com a (transitoriedade) efemeridade da existência humana. Todos os homens, ao seu tempo, estabelecem uma relação dialógica com o mundo, essa característica é intrínseca da nossa espécie. As experiências mudam, os conceitos mudam, mudam as sociedades, crenças e valores.

A filosofia é um indagar-se sobre o mundo. É descobrir em você, sujeito, e não no mundo os conceitos para tornar o mundo e a realidade algo significativo, com significação. A filosofia não tem que ter uma utilidade prática, como servir a um propósito específico ditado por uma lógica estabelecida pela sociedade, também não é mera contemplação, mas sim, dar uma significação racional ao mundo e indiretamente se estabelece relações mais harmônicas e igualitárias (isonomia). Quanto mais avançamos pela via da racionalidade, mais nos afastamos do caminho da violência, afirmavam os Antigos (Aristóteles). Na prática nem sempre isso acontece, mas isso ocorre pelo mau uso da racionalidade e não como algo inerente da racionalidade, na verdade configura uma contradição, é que a racionalidade transformada em instrumento, desvinculada de uma crítica sobre os seus fins, se perde diante de objetivos egoístas.

\section{O PAPEL DA FILOSOFIA NA EDUCAÇÃO}

Para o Estado a Filosofia enquanto uma disciplina do currículo do Ensino Médio tem por objetivo desenvolver habilidades necessárias para o pleno exercício da cidadania, contribuindo para a manutenção da ordem vigente. Nietzsche, como afirma Xavier, se utiliza de um procedimento genealógico para identificar, denunciar e combater esse status quo:

A genealogia investiga as práticas da cultura, é um procedimento de relação de palavras, conceito e valores a formas de vida, a tipos que têm sua realidade configurada pelo modo como vivem, pelas escolhas que fazem. A educação também está associada a modos de vida, a modos de ser, de avaliar e de apreciar. A genealogia e a filologia através dos exames das palavras, fazem estes tipos aparecer, mostram a s forças que estão agindo, os interesses que estão sendo mobilizados a confirmar uma pretensão, um valor (XAVIER, 2010, p. 7).

Dessa forma, a Filosofia no seu agir pedagógico, não pode ser apenas um instrumento de inserção dos jovens na sociedade, mas sim de investigação e ser uma ferramenta que possibilite transformações significativas da sociedade, repensando os valores estabelecidos. Deve-se repensar o próprio conceito de cidadania, de sociedade e os demais conceitos que estruturam essa realidade social.

A filosofia é um indagar-se sobre o mundo, sobre o sujeito no mundo. Um pensamento de ordem superior sobre a realidade. Assim, quando criamos conceitos, criamos realidades. Pode existir uma realidade objetiva, mas o que fazemos é uma interseção entre a realidade objetiva e a construída pelo sujeito que vivencia a experiência de estar no mundo (sentir e pensar a sua existência e o mundo), temos uma percepção do mundo que só pode ser estabelecida pelo sujeito no mundo. Viver a experiência para posteriormente conceituar.

Os jovens têm que viverem experiências reais do mundo para estabelecer uma relação autêntica com a filosofia. Ou seja, a filosofia tem de ir ao encontro da realidade dos estudantes adentrar em suas vidas de forma verdadeira e não por intermédio de problematizações artificiais sem ligação com o cotidiano dos estudantes, para que a reflexão não seja um simples pensar especulativo sobre um tema. O pensar sobre, exige a experiência de, para adquirir uma significa- 
ção verdadeira. Só podemos discorrer com propriedade sobre o que conhecemos de fato pela experiência. Nesse caso experiência é entendida como:

(...) um acontecimento irrepetível que, marcado pela contingência e a singularidade, implica a passividade de um espaço-sujeito que dá lugar a que algo nele aconteça. Experiência tem a ver com páthos, com ser afetado, tocado e tomado a entrar em cadência daquilo que toca, com o que toca, nos toma. Se o experimento mostra os resultados objetivos de uma conquista, a experiência é uma comoção que nos conquista e deixa entranhada em nós a marca de seu acontecimento (XAVIER, 2010, p. 110).

A experiência precede a formulação conceitual. Situações hipotéticas resultam em conceitos igualmente hipotéticos desvinculado do seu valor de verdade. Não há uma correspondência real (interseção) entre o conceito elencado o sujeito e o objeto no mundo, pois falta a experiência, a vivência. Assim, a Filosofia na Educação tem que priorizar as experiências dos estudantes e os conceitos que norteiam e definem o seu agir, a sua relação com o mundo. Os alunos são seres no mundo, agem a partir de relações estabelecidas e mediadas pelos conceitos instituídos pela sociedade. O objetivo de ser ofertada a Filosofia para os jovens, do ponto de vista pedagógico/ docente é que eles consigam dar uma significação a sua experiência de ser um sujeito no mundo. Uma significação ao mundo a partir de suas próprias experiências particulares, singulares. A experiência consciente da autonomia adquirida em que consiste a vida humana e a sua interação (intrínseca) com o mundo. A filosofia estabelece pelo pensamento crítico o conceito que estrutura e dá sentido à realidade.

Filosofar a partir de problemas, como propõem Deleuze e Gattari:

Um ensino de filosofia baseado na pedagogia do conceito significaria um maior investimento na problematização, isto é, na colocação do problema mais do que nas soluções. Não que o produto do pensamento (o conceito) não seja importante; mas sua produção só será possível pela vivência do problema e é importante que a produção do conceito não seja conclusiva, mas instigadora de novos problemas $(2013$, p.126).

Os conceitos que estruturam as vidas e suas percepções da realidade, as visões de mundo para criar realidades autênticas, conceitos coerentes com suas experiências de seres imersos no mundo. Protagonizar a experiência de sentir, pensar o mundo. Indagar, questionar-se. A vida é a autonomia oferecida à matéria, mas a plenitude dessa autonomia é somente alcançada quando se tem essa experiência proporcionada pelo mundo, decodificada, sendo criada pelo sujeito a sua respectiva significação, fruto de um tipo especial de pensamento de ordem superior, crítico, o pensar filosófico. Um pensamento edificante que cria conceitos que respondem, acalantam, pois tornam essa experiência em algo pleno, com significação.

\section{FILOSOFIA, POR QUE ESTUDAR?}

Estudar para viver com autonomia intelectual; estabelecer uma visão de mundo, a partir de 
suas próprias experiências de um sujeito no mundo. A experiência é a única forma de estabelecer uma relação com o mundo, é uma mediação, não há outra experiência concreta para o sujeito fora do mundo. A autonomia se alcança pelo exercício retilíneo de colocar a Razão ao propósito de estabelecer as estruturas que compõem a realidade por intermédio dos conceitos. São eles, os conceitos, que se entrelaçam se aproximam, se repelem se transformam em um todo que constitui a realidade.

Os conceitos não são o Ser em si, são definições criadas a partir da experiência sensível, empírico. Portanto, tendem a serem relativos aos sujeitos, é uma experiência singular, individual e intransferível e impossível de ser compartilhada na plenitude, logo não tem caráter universal. Por isso, os confrontos, embates são necessários para desvelar preconceitos e a ignorância que permeiam alguns conceitos estabelecidos pela sociedade. Dessa forma, viver a experiência, criar conceitos é também combater conceitos falaciosos, incoerentes, incongruentes com a realidade do sujeito no mundo.

O estudante tem que aprender revisar os conceitos estabelecidos pela sociedade e ser crítico e criterioso ao construir para si conceitos que balizarão seu agir no mundo, a sua compreensão desse mundo, isento de interferência externa (sociedade), mas paradoxalmente construídos pela própria experiência vivenciada em sociedade. Trata-se de uma relação entre o mundo externo/sensível, mas racionalmente depurado das doxas, preconceitos. Racionalidade, pensamento crítico e objetivo, mas a experiência empírica também é composta pela subjetividade do sujeito. É uma soma de sentir e pensar o mundo, criando uma significação racional a experiência; elencando conceitos que definem o Ser e o seu entendimento sobre o mundo.

Ensinar filosofia, ou seja, filosofar, é imprescindível para ter uma postura crítica em relação ao mundo e nas interações sociais. Para que esse objetivo seja alcançado deve-se desenvolver habilidades intelectuais para se refutar conceitos arbitrários, dogmáticos, falaciosos, axiomas supersticiosos, pensamento egoístas, instituídos e difundidos ao/e pelo senso comum, que estruturam a sociedade há gerações. Digo: ciência, religião, e as ideologias em que em alguns casos há somente uma alteração da natureza do dogma. A ciência constitui para si tantas verdades dogmáticas quanto a religião. Veneramos as verdades efêmeras das ciências. É o ser humano se perdendo na sinuosidade do seu pensamento racional. As verdades são efêmeras, os sujeitos são efêmeros, os conceitos estão circunscritos ao momento do sujeito no mundo. Seu conceito, sua visão de mundo, morrerá com ele, sua experiência única, singular, acabar-se-á com ele.

Deve-se desenvolver o senso crítico; a capacidade de argumentação; de análise, dissecar as afirmações alheias; erigir sínteses. Assumir uma postura tal qual a de Sócrates na pólis grega: analisar o discurso de seus interlocutores, confrontar ideias.

O professor de filosofia tem que trazer os conceitos para o contexto atual, o tempo presente. Analisando o valor de verdade de cada sentença, o teor da verdade, o conteúdo da verdade de cada argumento que constituem o conceito e a sua correspondência com o objeto que ele decorre, para verificar sua plausibilidade. Há uma outra situação, inversa a essa, em que criamos um conceito, quiçá ser universal, mas não há uma correspondência no mundo por dificuldades, situações intencionais ou contingenciais da vida em sociedade, a saber: justiça, democracia ou uma lei moral. Nesse caso o sujeito vive a experiência de um Ser no mundo, um sujeito incluso em uma coletividade que sente, abstrai, pensa, cria para si e compartilha com os outros um determinado conceito, mas esse conceito não tem a força de se realizar na plenitude.

Portanto, as aulas de filosofia têm seu motivo de ser alicerçado na busca pela compreensão do mundo e dos seres humanos e suas relações que se dão pelos conceitos estabelecidos, que estão em voga e aqueles que aspiramos que venham a compor de fato a estrutura conceitual que organizam a vida em sociedade. Os entraves estão nos objetivos egoístas que os homens estabelecem no plano individual, que têm reflexos na coletividade. É salutar rever os conceitos motivadores de projetos individuais egoísticos, pois esse também é papel da filosofia, enquanto uma disciplina da grade curricular do ensino regular. 


\section{O QUE ESTUDAR?}

Devem-se estudar os conceitos. Começar pelos conceitos? Não! Partir da experiência, a experiência real dos alunos. Essa experiência que está ali na sala de aula, na pluralidade, o modo que cada um na sua individualidade sente o mundo e cria uma concepção de realidade, mesmo que ainda estruturado por conceitos recebidos pela família, escola, pela sociedade. A experiência sendo construída, na vivência real dessa experiência. Ou seja, na experiência da vida sendo vivida. Buscar a as significações que essas experiências suscitam. Entender as conexões entre os conceitos, entre os conjuntos de conceitos.

São os conceitos que constroem as relações, criam conexões entre as pessoas e determinam o agir humano. Os rearranjos conceituais geram conflitos no interior de uma coletividade, é um devir constante, como constante assim é o fluxo das gerações humanas que convivem e se sucedem na dinâmica da transitoriedade da vida humana. A trajetória humana segue um fluxo constante, mas assim como um rio caudaloso que se esguia, ora entre montanhas, ora numa planície, ele é sinuoso. Como sinuosa é o uso da nossa racionalidade, e paradoxalmente, não há uma retidão na racionalidade e quando se busca esse caminhar retígrado, negligencia-se a subjetividade, o sentir. O agir humano, fazendo parte desse agir a criação de conceitos, é composto pela racionalidade e subjetividade. O pensar racional e o sentir são aspectos inerentes da constituição da espécie humana.

\section{COMO "ENSINAR"?}

Há muitas maneiras e caminhos possíveis a serem percorridos pelos docentes. No entanto, o melhor caminho é aquele em que o professor consiga alcançar os objetivos propostos. $\bigcirc$ professor tem que ter clareza de onde quer chegar em/com suas aulas, mas também tem que permitir, "dialogar com o improviso", com o não planejado para que novos caminhos e problemáticas sejam trazidos pelos alunos. Para elaborar estratégias de ensino eficazes, tem que estabelecer uma metodologia flexível e ter disposição para estar sempre reavaliando a práxis pedagógica.

O professor de Filosofia tem que se valer de todos as ferramentas possíveis para iniciar e realizar a reflexão filosófica, o mundo materializado no universo das manifestações e realizações humanas constituem o instrumental necessário para a práxis filosófica, o voltar-se sobre o mundo, ação de pensar o mundo a partir das experiências vividas pela a espécie humana ao longo de sua trajetória. Arte, as tradições filosóficas, a ciência e religião, todas as manifestações humanas são subsídios para se pensar filosoficamente.

Há uma mudança cultural significativa em curso, a sociedade ocidental está passando de uma cultura letrada para uma cultura imagética e isso acarreta em um descompasso entre escola/professor e os alunos. Os alunos estão inseridos em uma realidade em que suas experiências são permeadas pelo elemento visual/imagem. O professor pode estreitar a relação entre Filosofia e Arte, sem negligenciar a importância dos textos filosóficos para suscitar esse movimento de pensar a realidade; pensar o mundo e conceitos que lhe dão uma significação. As artes alargam o horizonte de percepção da realidade, ela pode assumir uma postura crítica contestatória e provocativa.

A arte não pensa menos que a filosofia, mas pensa por afectos e perceptos (...) O plano de composição da arte e o plano de imanência da filosofia podem deslizar um no outro, a tal ponto que certas extensões de um sejam ocupadas por entidades do outro (DELEUZE; GATTARI, 1992, p. 81). 
O objetivo da filosofia e da arte é extrair as sensações que remetam o sujeito a reflexão, inicialmente uma crítica, uma contestação do real, avançando para o pensar outros mundos possíveis. Quando vivemos na linearidade dos acontecimentos do cotidiano satisfeitos com a mediocridade de velhos conceitos, o nosso horizonte de percepção é reduzido. No entanto, quando procuramos viver o mundo com a experiência das artes há um alargamento da nossa compreensão sobre a realidade:

Julio Cabrera entende a filosofia orientada unicamente pelo intelecto sem a participação sensível e emocional como filosofia "apática". Talvez a compreensão de si e do mundo, exija a combinação de razão e afetividade, o que leva criar o conceito de "razão logopática". (XAVIER, 2010, p. 41).

O filósofo pela sua definição é o amigo do saber, do conhecimento, nutre um sentimento pela sabedoria, carrega em si um duplo sentimento o desejo incessante de conhecer a verdade e a angustia de saber que é um processo sem fim. Assim, cabe ao professor/filósofo compartilhar esse sentimento e o desejo de conhecer com os estudantes.

A filosofia auxilia a distinguir as demandas verdadeiras e necessárias das supérfluas e artificiais. Estas prendem os homens numa realidade produzida, criada, que mantêm os indivíduos em uma artificialidade de agir e pensar. Deve-se romper com esses conceitos que permeiam o real, se libertar do cárcere dos engodos conceituais em que a humanidade vive. A arte nos aproxima dessa outra dimensão possível da realidade permeada pela a subjetividade. Criar outros mundos possíveis desvinculados dos sistemas conceituais conservadores e mantenedores do status quo.

A quem interessa a homogeneização e padronização da sociedade em suas crenças e valores? Os conceitos mantidos arbitrariamente de forma imutável e absoluto servem a o propósito de manter a ordem estabelecida. A vida, a experiência do Ser no mundo é um devir, por isso a filosofia não cessa de buscar novas respostas para antigas e atuais e novas indagações, novos olhares sobre o mesmo objeto de investigação: o mundo, o homem e o universo das interações. Mudam os sujeitos, os contextos, a que mudar os conceitos. Eles não são faróis que sinalizavam o caminho seguro aos navegadores, não! Os conceitos são os mares tempestuosos em que as tripulações têm que se debaterem para permanecerem vivos, viver com autonomia intelectual, é a única forma de encontrar o melhor caminho no caos e não sucumbir aos vagalhões.

\section{A EXPERIÊNCIA DA DOCÊNCIA}

\subsection{A escola: cárcere, disciplina e controle.}

A escola reproduz em nível local, o aparato de controle social estabelecido pelo Estado. Os alunos têm uma percepção da escola que se aproxima da ideia de uma prisão, e isso é uma decorrência do aparato de controle instituído e do regramento que dita a dinâmica da rotina escolar. Esses mecanismos visam manter "tudo sobre controle", disciplinar os estudantes e manter a ordem estabelecida por meio da coerção.

Os instrumentos de controle são as regras e o seu descumprimento pode acarretar para o "infrator" sanções e punições; ou o ambiente por excelência da prática pedagógica, a Sala de Aula, o cárcere! Alunos perfilados, enfileirados aguardando o mestre quem vem ao encontro deles para transmitir seu conhecimento. Não é fato isolado que os professores se utilizem da coerção para conseguir manter a disciplina e controle em sala de aula: Em um dado momento da prática 
pedagógica perguntei para uma turma "indisciplinada" como que eles ficavam quietos nas aulas de uma determinada disciplina. Eles me responderam em coro: "Nós temos medo dela"! Bem, para um professor, por mais difícil que seja a relação com alunos, não pode pautar suas atividades na coerção, mas isso tem sido a regra, não a exceção.

Assim, somos levados ao seguinte questionamento: qual é origem do desinteresse dos estudantes? São muitas as prováveis respostas, mas uma delas, consiste no descompasso entre escola/ professor e alunos. Uma crise do paradigma de ensino. É Salutar redefinir o papel da escola na sociedade e o significa de "ensinar" e "como ensinar". Deve-se propor alternativas à "escola prisão". Local de transmissão e reprodução de um conhecimento proveniente apenas de instâncias superiores de ensino. A escola também pode e deve ser um local de produção de conhecimento, de troca de experiências significativas, vivências reais, não meramente um cotidiano pautado pela formalidade das regras estabelecidas, uma artificialidade de atividades realizadas de forma automática, robotizada, que a cada bimestre ou trimestre serão esquecidos e descartadas a cada final de ano para dar espaço ao material do próximo ano letivo.

\section{2 A carga horária de Filosofia}

Nas reuniões pedagógicas e conselhos de classes, ou no convívio diário com colegas de outras disciplinas é perceptível a inexpressividade das disciplinas da Área de Humanas no que diz respeito à importância e participação na produção das atividades da escola. A grade curricular e a carga horária das disciplinas denotam o grau de importância que é atribuída a cada uma delas. Falando especificamente da disciplina de Filosofia pode-se concluir que ela se constitui como uma disciplina de terceira ordem, compondo com a Sociologia e Artes a tríade das enjeitadas. Isso se expressa pela carga horária de uma hora aula semanal, ou no máximo duas horas aula por semana. O grau de relevância de uma disciplina fica evidenciado pela sua carga horária.

E qual é o critério utilizado para definir quão importante é uma disciplina? Se é que essa distinção seja algo verdadeiro, tanto do ponto de vista pedagógico quanto epistemológico. A relevância de cada disciplina é definida por um aspecto meramente valorativo, constituído pela a utilidade prática que cada disciplina se propõe. Então, pode-se concluir que: uma disciplina tende a ser importante de acordo com aquilo que ela possa contribuir principalmente para o desenvolvimento cognitivo do aluno, visando o seu aproveitamento futuramente no "mundo do trabalho", em detrimento de um desenvolvimento de aspectos importante para convívio em sociedade, enquanto cidadão. Uma ressalva, a escola tem sim uma preocupação em formar cidadãos, mas estes são moldados, condicionados a pensar dentro de uma lógica estabelecida e visa a manutenção de um status quo. A escola não forma cidadãos para pensar outras realidades, outros mundos possíveis.

\subsection{A Filosofia e os congêneres: incompreensão, pré-conceitos e segregação.}

Imaginário docente sobre a disciplina de Filosofia: "Anedotas docentes" que corroboram o desprezo pela Filosofia:

Reunião pedagógica para redistribuir a carga horária dentro de cada área de ensino, detaIhe, matemática não faz parte da Área de Humanas:

"A Filosofia não precisa de duas horas por semana, não tem conteúdo para isso. Dê para a Matemática um período, eu preciso mais"; "Filosofia é só conversa fiada"; "Filosofia não é útil pra nada".

Esses exemplos e tantos outros que fazem parte do cotidiano da prática docente, denotam a visão que os colegas e demais setores da escola têm sobre a Filosofia. Penso que isso decorre da própria incompreensão do que seja a filosofia e principalmente por ela não se enquadrar ou 
contribuir para a manutenção da lógica vigente: Uma formação voltada quase que exclusivamente para o mercado de trabalho. Se a sociedade tem um olhar míope sobre a filosofia, por sua vez nas escolas o olhar é hipermetrope. Aquela não enxerga de longe e essa não enxerga de perto o verdadeiro valor da filosofia. Para a sociedade só tem valor aquilo que apresenta em si um valor de utilidade, configurando um pragmatismo.

\section{4 As expectativas dos estudantes: Do Enem ao "bate-papo".}

Situação não muito diferente é a relação da filosofia com os estudantes. Há um conjunto de fatores que dificultam a aproximação da filosofia com os alunos: Eles têm uma formação deficiente em linguagens, principalmente em leitura e interpretação de textos. Para a professora Ingrid M. Xavier "o comprometimento da discursividade do estudante brasileiro representa, portanto, um dos entraves ao campo teórico da filosofia e seu ensino" (XAVIER, 2010, p. 39).

A filosofia não é ofertada no ensino fundamental na rede pública, fato que gera um desconhecimento total do que seja filosofia; por vezes, a disciplina é ministrada por professor que não são capacitados, ou seja, de outras áreas; carga horária restrita; todos esses aspectos contribuem para que os estudantes não se dediquem a disciplina. A sua importância se resume ao Enem, pois de um modo geral, eles ratificam, compartilham a mesma ideia que a escola e a sociedade têm sobre a filosofia seu valor prático/pragmático.

Para um grande número de adolescentes a filosofia se configura como um "bate-papo" uma conversa despretensiosa; por vezes, algo sem sentido se o professor exagerar na erudição; também é aquela aula em que se faz atividades pendentes de outras disciplinas. A exceção é o "Clubinho da Filosofia", que são aqueles alunos que tem uma "pré-disposição natural" às discussões filosóficas, eles constituem algo em torno de dez porcento da turma (três ou quatro alunos). De alguma forma são esses alunos que fazem as aulas acontecerem, contribuem para que elas não se tornem apenas um monólogo do professor frente a uma turma prostrada, desmotivada, sem interesse. Por vezes, são eles que conseguem trazer os colegas para as discussões filosóficas, para as atividades das aulas. Geralmente o "clubinho da filosofia" é composto por alunos que têm um hábito, um gosto pela leitura e uma postura crítica, elementos essenciais para o filosofar.

\section{5 O professor de Filosofia: tarefas hercúleas.}

O professor de Filosofia de ensino médio vive a prática docente em um ambiente de adversidade e incertezas. Não vejo nas escolas, outro profissional que se questione tanto quanto ele sobre a sua própria prática docente. Ele tem que em primeiro lugar constituir para si uma definição do que ele entende por filosofia. Posteriormente, pensar e criar estratégias de ensino, desenvolver um método de ensino adequado a realidade escolar e a do educando para ter êxito em sua prática. Tem que estabelecer objetivos e ao mesmo tempo permitir que novos caminhos novas problemáticas venham a surgir, aprendendo a trabalhar com o improviso, com o inesperado, o não-planejado; dar liberdade aos alunos; tornar as aulas experiências significativas para que não sejam abandonadas ao final do ano com o "fechar dos cadernos".

Penso que, o professor tem que se desafiar a descer do pedestal, do púlpito e despir-se do seu verniz acadêmico que o recobre e protege, e de certa forma o afasta dos educandos. Ao professor cabe mediar, criar um ambiente propicio para que os alunos consigam desenvolver atividades significativas, viver as experiências e não apenas tomar contato com a realidade de forma artificial. E estar sempre repensando a sua prática docente. "Sábio é aquele que sabe que não sabe, pois o pretenso Sábio por tudo saber, pensa que nada mais tem a aprender e passa a professar". 


\section{CONSIDERAÇÕES FINAIS}

Concluindo, a tarefa de tornar a filosofia em uma disciplina do currículo escolar, por si só já se configura como algo desafiador. Mas, além do problema da adequação, muitos são os entraves para o ensino de filosofia no ensino médio: os objetivos delimitados pelo Estado, a estrutura das instituições de ensino que de certa forma como foi demonstrado vão de encontro com a própria natureza da filosofia, pois a escola é uma estrutura arcaica, repressora e disciplinadora. Há também, baixo nível de desenvolvimento intelectual dos estudantes, a falta de familiaridade com textos e por consequência a dificuldade de interpretação; a heterogeneidade dos estudantes, realidades sócias díspares que dificulta a realização de um trabalho homogêneo exigindo mais atenção empenho dos docentes. Há o problema da carga horária restrita e da não valorização das aulas de filosofia.

Por fim, é necessário desenvolver uma metodologia de ensino de filosofia que esteja em "sintonia" com a realidade dos educandos e que de alguma forma crie atrativos para inseri-los na filosofia/filosofar. A experiência docente pautada em uma metodologia de ensino em que se estabelece um diálogo, uma parceria entre filosofia e arte tem logrado bons resultados. Assim, a filosofia deixa de ser apenas uma atividade teórica de análise conceitual e assume uma condição de atividade prática, tornando-se uma experiência real vivenciada por um sujeito, que vai pensar o mundo a partir dessa experiência.

\section{REFERÊNCIAS:}

CARVALHO, Marcelo; CORNELLI, Gabriele (Orgs.). Ensinar filosofia. Cuiabá, Central de Texto, vol. 2, 2013.

DELEUZE, Gilles; GUATTARI, Félix. O que é a filosofia? Rio de Janeiro: Ed. 34, 1992.

XAVIER, Ingrid Muller. $O$ que significam ensinar e aprender filosofia? Notas a partir de uma experiência no Colégio Pedro II. Tese (Doutorado em Educação) Rio de Janeiro, UERJ, 2010. 